\title{
O perfil do aluno de cursos técnicos ou Parem as máquinas: 0 aluno envelheceu
}

\author{
The profile of technical courses student or Stop the machines: the student got old
}

Paulo Tadeu Rabelo da Motta - Universidade Estadual Paulista - pamotta@assis.unesp.br

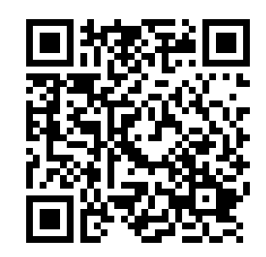

A vida laboral tem apresentado significativas e constantes mudanças nas últimas décadas, tanto do ponto de vista de práticas sociais como em termos de visões sobre o mundo do trabalho. As transformações ocorrem de uma maneira rápida e imprevisível, principalmente no campo das profissões. Em virtude da geração constante de atividades profissionais cada vez mais especializadas, os profissionais que estão atuando e as pessoas que pretendem ingressar em uma profissão veem-se impelidos a acompanhar as transformações que ocorrem no mundo do trabalho. Parece não haver mais certezas quanto à longevidade ou à obsolescência de funções e atividades profissionais; além disso, a formação cada vez mais precoce e os cursos de atualização são necessários para o ingresso e para a permanência em determinados cargos.

Diante desse quadro, os jovens em situação de escolha profissional têm recebido cada vez mais informações sobre o mundo das profissões e do trabalho via mídia, particularmente a voltada ao público jovem, urbano e de classe média. Na recente campanha política (2010) para o governo no estado de São Paulo, os cursos técnicos foram apontados como solução de problemas relacionados ao mundo do trabalho, pois a viabilização de mais vagas para atender uma demanda sempre crescente viria com a criação de novos cursos, em novas cidades e em novas regiões. Assim, com a certeza de colocação no mercado de trabalho, essa formação também contribuiria com o desenvolvimento do estado, suprindo a mão de obra técnica, ausente na maioria das regiões.

Não podemos nos esquecer de que a educação profissional, desde a sua implantação, carregou consigo o estigma ligado ao seu status, que nunca foi dos melhores, 
pois sempre esteve presente no discurso educacional como o tipo de educação oferecida aos menos favorecidos economicamente.

Os jesuítas foram os primeiros professores do Brasil e, de acordo com Sablich (2007), fundaram a primeira escola de ensino primário brasileira, em 1549, na cidade de Salvador.

O documento comemorativo dos 100 anos da Rede de Educação Profissional e Tecnológica, elaborado pelo Ministério da Educação (BRASIL, 2009), informa que os índios e os escravos foram os primeiros aprendizes de ofícios, ainda no período Colonial. Desde então, aquela forma de ensino era vista "como destinada somente a elementos das mais baixas categorias sociais" (FONSECA, 1961, p. 68).

No conjunto de três obras de Cunha $(2005 a, b, c)$, é possível notar a dualidade que se estabeleceu a partir desses acontecimentos. Na trilogia citada, fundamental para estudos dessa temática, a educação nacional parece fendida. De um lado, para a elite e os filhos dela era oferecido o Ensino Propedêutico; de outro, a Educação Profissional, que era destinada à população pobre e aos filhos dos trabalhadores. Percebe-se que tais diferenças atravessaram séculos, governos, e sustentam-se até hoje, ora travestidas de iniciativas de cunho liberalista, como começaram, ora travestidas de "políticas públicas", geradas nos gabinetes do poder. Cunha $(2005 a, b, c)$ argumenta que o Império deixou um legado para a República - a aliança de liberais, positivistas e monarquistas magoados com os rumos da política -, fatos que certamente se refletem na Educação, atualmente.

Dando um significativo e proposital salto no tempo, com a eleição de Juscelino Kubitschek (1955-1960), uma grande transformação era desejada no setor produtivo. Entretanto, não ocorreu como se esperava, em razão até das condições econômicas mundiais. A construção de Brasília e os planos ufanistas do governo de percorrer 50 anos em cinco mantiveram ainda acesas as chamas do tão buscado progresso. Após o governo de JK, Jânio Quadros assume em janeiro e renuncia em agosto de 1961. Em dezembro de 1961, em meio ao caos da renúncia de Jânio Quadros e às incertezas que se cultivaram sobre o governo de João Goulart, foi promulgada a Lei de Diretrizes e Bases da Educação Nacional que, segundo Biagini (2012, p. 9), trouxe consigo a "primeira tentativa de articulação dos dois sistemas de ensino, a partir da equivalência plena entre os cursos propedêuticos e os profissionalizantes".

Foi a partir dessa Lei que o aluno da Educação Profissional poderia almejar a continuidade de seus estudos, pois poderia submeter-se ao vestibular. Foi mais uma das ações do governo que atingiram plenamente os objetivos (do governo).
Os alunos oriundos da Educação Profissional não dispunham do arsenal propedêutico que era exigido nos exames seletivos para a Universidade; portanto, seguindo os objetivos traçados, mantinha-se o mercado muito bem abastecido de técnicos, prontos para o trabalho e dispostos a cumprir sua nobre missão de atender ao ideário do Liberalismo e, logo em seguida, da ditadura militar, que se avizinhava. E toda essa situação era vivenciada com o aval do aluno da Educação Profissional e, por conseguinte, de sua família, a qual assumia a culpa por não conseguir ultrapassar os limites que eram muito bem estabelecidos pelas políticas do governo.

Com o golpe militar, em 1964, o poderio dos Estados Unidos da América também estendeu suas garras sobre a Educação brasileira. Assim, na área da Educação, muitos acordos foram realizados, sendo o mais famoso e importante a parceria que se estabeleceu entre o MEC e o Usaid $^{1}$, refletindo fortemente na LDB $n^{\circ}$ 5.692, de agosto de 1971.

A Lei n 5.692/71, já em seu Art. $1^{\circ}$, apregoa que o verdadeiro sentido da Educação está no "exercício consciente da cidadania", que poderá ser exercido por meio do trabalho. Contudo, para que recordemos, o presidente do Brasil era o General Emílio Garrastazu Médici e o Ministro da Educação o então político e ex-tenente coronel do exército Jarbas Passarinho.

Os anos de ditadura militar passaram e trouxeram os anos 90. Antes um pouco, em 1985, José Sarney assume a presidência da república, representante da Arena, partido que servia de fachada legal à ditadura militar. Com Tancredo Neves, a busca por dias melhores foi sepultada junto com ele, naquele dia 21 de abril de 1985, exatamente 39 dias depois de trazer nova esperança ao povo brasileiro, tendo sido eleito, mesmo que por um colégio eleitoral, o primeiro presidente civil.

1 MEC-Usaid: Acordo que incluiu uma série de convênios realizados a partir de 1964, durante o regime militar brasileiro, entre o Ministério da Educação (MEC) e a United States Agency for International Development (Usaid). Os convênios, conhecidos como acordos MEC/Usaid, tinham o objetivo de implantar o modelo norte-americano nas universidades brasileiras mediante uma profunda reforma universitária. Segundo estudiosos, por meio do acordo MEC/Usaid, o ensino superior exerceria um papel estratégico porque caberia a ele forjar o novo quadro técnico que desse conta do inovador projeto econômico brasileiro, alinhado com a política norte-americana. Além disso, visava à contratação de assessores americanos para auxiliar nas reformas da educação pública, em todos os níveis de ensino.

A discordância com os acordos MEC/Usaid se tornaria, na época, a principal reivindicação do movimento estudantil. Diante da violenta oposição levantada nos meios intelectuais e estudantis contra os acordos MEC/Usaid, o governo criou, em 1968, um Grupo de Trabalho encarregado de estudar a reforma e propor outro modelo (MENEZES, 2002). Para estudos mais aprofundados a esse respeito, o que não é o nosso caso no momento, é fundamental consultar as obras de José Oliveira Arapiraca (1982), Otaíza Romanelli (1978), Luiz Antônio Cunha e Moacyr de Góes (1985), entre outros. 
Na década de 90, o Ensino Técnico foi se estabelecendo, portanto, de acordo com o percurso histórico aqui desenhado, ou seja, partindo da estruturação da lógica capitalista como modelo de organização da sociedade" (BIAGINI, 2012, p. 15).

Aos trancos e barrancos, o Ensino Profissionalizante consolidou-se, tanto que a LDB de 1996, Lei n 9.394/96, vigente até agora, sancionada por Fernando Henrique Cardoso e com a indelével colaboração de Darcy Ribeiro, dedicou para a modalidade um capítulo inteiro, que, no nosso entendimento, pouco avançou no que concerne à cidadania. Preocupados com as falsas promessas de políticos em campanha e, em decorrência disso, com o interesse repentino de uma parcela da população por facilidades na formação e na busca do emprego, decidimos nos debruçar sobre tais aspectos, buscando investigar o perfil do aluno que procura pelas vagas dos cursos técnicos, especificamente as oferecidas pelo Centro Paula Souza, que congrega, no estado de São Paulo, cerca de 203 escolas técnicas (Etecs) e 51 faculdades de tecnologia (Fatecs) espalhadas por 157 cidades do estado. Temos plena consciência de que generalizações são temerárias, ou seja, ao investigar uma escola do estado de São Paulo não é possível afirmar que teremos um retrato do Brasil. A despeito de generalizações, nosso maior objetivo consiste em traçar um perfil do aluno que compõe o corpo discente da escola técnica e chamar a atenção do mundo educacional para uma nova realidade que se avizinha.

O Centro Paula Souza iniciou suas atividades em 1969, porém, desde 1963, o Conselho Estadual de Educação vinha se reunindo com o objetivo de atender a uma demanda da indústria paulista, que se expandia muito e necessitava de mão de obra treinada. A ideia ganhou um aliado, o então governador Roberto Costa de Abreu Sodré, que assumiu o posto em 1967. Em 1969, por meio de Decreto-Lei, foi criado o Centro Estadual de Educação Tecnológica Paula Souza de São Paulo, autarquia destinada ao ensino tecnológico, posteriormente alterado pela Lei $n^{\circ} 4.672 / 85$. Atualmente, alardeia-se, por intermédio da mídia, um aumento superior a 50\% no número de vagas oferecidas para o Ensino Técnico, o que demonstra um grande incentivo do governo paulista para com esse tipo de Ensino. A variedade de cursos oferecidos é imensa e, em alguns casos, fundamental para o desenvolvimento regional, sendo possível reconhecer que alguns cursos só são oferecidos para determinadas regiões, como, por exemplo, o curso de "Curtimento", que só é oferecido na cidade de Franca, em virtude da indústria do calçado; ou o curso de "Gestão da Produção de Enxovais e Decoração", que só é oferecido em Ibitinga, cidade que alcançou renome nacional por causa da produção do bordado; ou ainda o curso de "Processamento de Carnes", oferecido somente em Presidente Prudente, cidade reconhecida como dona de um dos maiores rebanhos bovinos do Estado e por abrigar diversos frigoríficos. Considerando essa situação, podemos depreender o papel do governo em formar e suprir empresas privadas de mão de obra técnica especializada.

Nosso trabalho de investigação foi impulsionado, também, pela constatação recorrente do interesse por cursos técnicos, por parte de uma população que antes só manifestava interesse pelos cursos superiores. Trabalhamos, há mais de vinte anos, na orientação de jovens em situação de escolha profissional e temos notado uma mudança nas perspectivas profissionais dessa população que procurava por nossos serviços. ${ }^{2}$

\section{Metodologia}

Elaboramos um questionário, cuja versão final ficou composta de 27 questões, nas quais o sujeito poderia anotar uma ou mais respostas, de acordo com a orientação explicitada em cada uma delas; era um teste autoaplicável cujas respostas foram digitadas em um banco de dados (Planilha Eletrônica do Microsoft Excel; 2007) e a análise dos dados foi realizada com a utilização do software Statistica 6.1 (StatSoft, Inc.). Os dados foram analisados por meio de estatística descritiva, sob a forma de frequência simples e percentual.

Para o levantamento que nos levaria a identificar a classe socioeconômica, optamos por utilizar o critério da Associação Brasileira de Institutos de Pesquisa de Mercado (Abipeme) ${ }^{3}$, pois esse critério inova ao desprezar ganhos salariais e valorizar a situação educacional do chefe da

2 CPPA-Unesp/Assis-SP: Centro de Pesquisa e Psicologia Aplicada Dra. Betti Katzeinstein, clínica-escola do curso de Psicologia da Universidade Estadual Paulista "Júlio de Mesquita Filho", campus de Assis, interior do estado de São Paulo, cujos serviços são oferecidos gratuitamente.

3 O sistema atual de classificação da Abipeme tem uma longa história, permeada por esforços de seus pesquisadores em elaborar e atualizar instrumentos que possam retratar a população brasileira quanto ao perfil socioeconômico, e isso acontece desde a década de setenta do século passado. O critério que usaremos no presente trabalho é um aperfeiçoamento de um outro critério, da ABA - Associação Brasileira de Anunciantes, cujo objetivo era e é o de dividir a população em categorias, segundo determinados padrões de consumo ou, melhor ainda, separála por faixas potenciais de consumo. O critério Abipeme consegue seu objetivo criando uma classificação socioeconômica, por meio da atribuição de valores, a posse de alguns itens de conforto doméstico (aparelhos e serviços), além, é claro, da atribuição de valores ao nível de escolaridade do chefe de família, não valorando o item "salário", muito comum em outros critérios. Assim, entendemos que o critério torna-se mais justo ao não apenas quantificar, mas atribuir valor à posse de bens e serviços, bem como ao nível de escolaridade do chefe de família. Em JANNUZZI e BAENINGER, 1996, é possível obter mais informações sobre o critério da Abipeme. 
família, assim como a posse de bens e serviços.

A população-alvo constituiu-se de alunos regularmente matriculados e frequentadores dos cursos técnicos de uma Escola Técnica do interior do estado de São Paulo, em qualquer série ou momento do curso, pois o objetivo era abranger a maioria dos alunos matriculados no $2^{\circ}$ semestre de 2010. É salutar destacar que a população averiguada situa-se tanto na modalidade "subsequente", como na "concomitante" ou "integrado". No Centro Paula Souza é possível inscrever-se num curso técnico e cursar o Ensino Regular em outra escola ao mesmo tempo ou já tê-lo terminado antes.

Os questionários foram aplicados nas salas de aulas, com a colaboração da direção, entre outubro e novembro de 2010. E, dentro de um universo de 497 alunos matriculados nos cursos técnicos da escola, aplicamos 339 questionários. Todos os cursos estão representados em nossa amostra, atingindo $68,2 \%$ dos alunos matriculados. Cabe ressaltar que a presente pesquisa foi registrada e teve seu relatório final aprovado pelo Comitê de Ética em Pesquisa da Universidade Estadual Paulista "Júlio de Mesquita Filho", sob o $n^{\circ}$ 014/2010.

\section{RESULTADOS}

O questionário aplicado trouxe, logo de início, a constatação de que a população feminina é superior e também revelou a presença de pessoas entre 15 e 59 anos de idade, e a média dessa população ficou em 24,12 anos (desvio-padrão: 8,3), muito superior à esperada na seriação ideal.

Os alunos que responderam ao questionário estavam distribuídos por todos os cursos e períodos oferecidos pela escola.

Tabela 1 - Gênero e situação Familiar

\begin{tabular}{lcc}
\hline & Número de respondentes Porcentagem \% \\
\hline Gênero & 161 & 47,5 \\
Masculino & 178 & 52,5 \\
Feminino & & \\
Situação conjugal & 80 & 23,6 \\
Casado & 233 & 68,7 \\
Solteiro & 26 & 7,7 \\
Outros & & \\
Possui filhos? & 88 & 26,0 \\
Sim & 251 & 74,0 \\
Não & & \\
Moradia & 218 & 64,3 \\
Com os pais & 89 & 26,3 \\
Cônjuge & 32 & 9,4 \\
Outros & & \\
\hline
\end{tabular}

Foi solicitado do respondente que esclarecesse sua situação conjugal. Os dados tabulados nos revelaram que a maioria, 68,7\%, ou 233 dos 339, é solteira, e já buscando os dados referentes à questão posterior, verificamos que 250 ou 73,7\% não têm filhos e que a maioria dos alunos, $64,3 \%$ ou 218 entre os 339 respondentes, mora com os pais.

Pretendíamos, também, identificar a relação dos alunos com as novas tecnologias. Os dados obtidos a esse respeito compõem a Tabela 2.

A posse do computador pessoal deixou de ser um privilégio de poucos. Mais de $70 \%$ dos alunos respondentes o possuem e têm conexão com a Internet. É bem visível que nem todos possuem a máquina, mas mais de $96 \%$ têm endereço eletrônico. A Tabela 3 concentra os dados referentes ao que denominamos de costumes, pois retrata, em números, a situação trabalhista e como, ou em que atividade, o aluno que opta pelos cursos técnicos aproveita os momentos que tem de lazer.

Tabela 2 - As novas tecnologias

\begin{tabular}{lcc}
\hline Categorias & $\mathbf{N}^{\circ}$ de respondentes & Porcentagem \% \\
\cline { 2 - 3 } Posse de computador & 243 & \\
Sim, com Internet & 34 & 71,7 \\
Sim, sem Internet & 62 & 10,1 \\
Não tem & 270 & 18,3 \\
Sim & 64 & 79,7 \\
Não & 51 & 18,8 \\
Sem resposta & & 0,5 \\
MSN-Messenger & 309 & \\
Sim & 26 & 91,2 \\
Não & 04 & 7,6 \\
Sem resposta & & 1,2 \\
E-mail & 328 & \\
Sim & 10 & 96,4 \\
Não & 02 & 2,9 \\
Sem resposta & & 0,6 \\
\hline
\end{tabular}

A situação trabalhista dos pesquisados aponta para mais de $60 \%$ de trabalhadores, dos quais mais de $19 \%$ o fazem sem o devido registro em carteira. Uma parcela bastante significativa, mais de $36 \%$, tem apenas a atividade estudantil como afazer diário.

Quanto às atividades de lazer aferidas, 69\% dos alunos que optam pelos cursos técnicos afirmam que a TV $(20,2 \%)$, os amigos (20,5\%) e a Internet (28,3\%) satisfazem tal necessidade. 
Tabela 3 - Costumes.

\begin{tabular}{lcc}
\hline \multicolumn{1}{c}{ Categoria } & $\mathrm{n}^{\circ}$ de respondentes & Porcentagem \% \\
\hline Situação trabalhista & & \\
Trabalha, sem carteira assinada & 66 & 19,5 \\
Trabalha, com carteira assinada & 143 & 42,2 \\
Não trabalha & 125 & 36,8 \\
Não responderam & 05 & 1,5 \\
Lazer & & \\
Internet & 95 & 28,3 \\
Amigos & 69 & 20,5 \\
TV & 68 & 20,2 \\
\hline
\end{tabular}

Tabela 4 - Dados familiares e socioeconômicos.

\begin{tabular}{|c|c|c|}
\hline Categorias & Número de respondentes & Porcentagem \% \\
\hline \multicolumn{3}{|l|}{ Quem mais contribui \$ } \\
\hline $\begin{array}{l}\text { O pai } \\
\text { O mesmo (o aluno) } \\
\text { A mãe }\end{array}$ & $\begin{array}{r}143 \\
66 \\
65\end{array}$ & $\begin{array}{l}42,2 \\
19,5 \\
19,1\end{array}$ \\
\hline \multicolumn{3}{|l|}{ Grau de instrução - Mãe } \\
\hline $\begin{array}{l}\text { Ensino Médio completo } \\
\text { Ensino Fundamental incompleto } \\
\text { Analfabeto } \\
\text { Superior completo }\end{array}$ & $\begin{array}{r}117 \\
88 \\
31 \\
40\end{array}$ & $\begin{array}{r}34,5 \\
25,9 \\
9,1 \\
11,7\end{array}$ \\
\hline \multicolumn{3}{|l|}{ Grau de instrução - Pai } \\
\hline $\begin{array}{l}\text { Ensino Médio completo } \\
\text { Ensino Fundamental incompleto } \\
\text { Analfabeto } \\
\text { Superior completo }\end{array}$ & $\begin{array}{r}112 \\
92 \\
33 \\
29\end{array}$ & $\begin{array}{r}33,1 \\
27,2 \\
9,7 \\
8,5\end{array}$ \\
\hline \multicolumn{3}{|l|}{ Classificação ABIPEME } \\
\hline $\begin{array}{l}\text { A } \\
\text { B } \\
\text { C } \\
\text { D } \\
\text { Profissões mais citadas-Mãe }\end{array}$ & $\begin{array}{r}09 \\
127 \\
138 \\
09\end{array}$ & $\begin{array}{c}3,2 \\
44,9 \\
48,8 \\
3,2\end{array}$ \\
\hline $\begin{array}{l}\text { Do lar } \\
\text { Doméstica }\end{array}$ & $\begin{array}{r}113 \\
51\end{array}$ & $\begin{array}{l}33,3 \\
15,1\end{array}$ \\
\hline \multicolumn{3}{|l|}{ Profissões mais citadas-Pai } \\
\hline Aposentado & 47 & 13,8 \\
\hline $\begin{array}{l}\text { Pedreiro } \\
\text { Motorista }\end{array}$ & $\begin{array}{l}22 \\
22\end{array}$ & $\begin{array}{l}6,5 \\
6,5\end{array}$ \\
\hline
\end{tabular}

Quanto ao grau de instrução de quem mais colabora financeiramente, podemos notar, com base na Tabela 4, que tanto o pai quanto a mãe possuem o Ensino Médio completo. Os pais apresentam números superiores a 30\% nesse nível de escolaridade e as mães trazem um índice um pouco acima (34,5\%).

Diante dos dados captados por meio dos questionários aplicados, é notória a concentração dos alunos nas classes $B$ e $C$, segundo os critérios de classificação da Abipeme.
Esses dados serão discutidos oportunamente.

Propositadamente, deixamos por último, para serem apresentados na Tabela 5, os dados referentes à situação escolar dos respondentes da pesquisa. Assim o fizemos, pois entendemos que os aspectos educacionais que buscamos elucidar por meio do questionário aplicado serão fundamentais para a composição do perfil do corpo discente. 
Tabela 5 - Situação educacional.

\begin{tabular}{|c|c|c|}
\hline Categorias & Número de respondentes & Porcentagem \% \\
\hline \multicolumn{3}{|l|}{ Cursou o Primeiro Grau } \\
\hline Escola pública & 304 & 89,7 \\
\hline Escola particular & 17 & 5,0 \\
\hline Maior parte pública & 07 & 2,1 \\
\hline Maior parte particular & 9 & 2,6 \\
\hline Não responderam & 2 & 0,6 \\
\hline \multicolumn{3}{|l|}{ Motivos para escolher o curso* } \\
\hline Qualidade & 208 & 61,7 \\
\hline Vagas no mercado & 155 & 46,0 \\
\hline Realização pessoal & 148 & 43,9 \\
\hline Gratuito & 126 & 37,4 \\
\hline Aptidões pessoais & 94 & 27,9 \\
\hline Ganho salarial & 83 & 24,6 \\
\hline \multicolumn{3}{|l|}{ O que mais espera do curso } \\
\hline Cultura geral & 19 & 5,6 \\
\hline Formação para o mercado & 243 & 71,7 \\
\hline Formação para os estudos & 73 & 21,5 \\
\hline Diploma & 02 & 0,6 \\
\hline Não responderam & 02 & 0,6 \\
\hline \multicolumn{3}{|l|}{$\begin{array}{l}\text { O que pretende ao concluir o } \\
\text { curso }\end{array}$} \\
\hline Trabalhar e estudar & 143 & 42,2 \\
\hline Prosseguir estudos - Universidade & 99 & 29,2 \\
\hline Trabalhar na área & 80 & 23,6 \\
\hline Não sei & 10 & 2,9 \\
\hline Trabalhar em qualquer área & 05 & 1,5 \\
\hline Não responderam & 02 & 0,6 \\
\hline
\end{tabular}

* neste item poderiam assinalar até três opções.

A grande maioria dos alunos, ou seja, um índice muito próximo de $90 \%$ é oriunda da Escola Pública, instituição em que esses alunos cursaram o atual Ensino Fundamental. Na Tabela 5, a tabulação do questionário aponta os motivos que levaram o aluno a escolher este ou aquele curso técnico. Entre 13 opções oferecidas, o questionário solicitava ao respondente que assinalasse no máximo três. A Tabela 5 aponta os seis mais citados pelos respondentes. Assim, a alternativa que dizia sobre a qualidade do curso oferecido foi a mais assinalada pelos respondentes, com índice percentual superior a $60 \%$, seguido da alternativa que destacava a disponibilidade de vagas no mercado de trabalho, citada por $46 \%$, e a terceira mais citada foi a alternativa que apontava a possibilidade de realização pessoal, com $43 \%$ dos respondentes assinalando-a.
O que mais espera do curso foi o desafio proposto, e das quatro alternativas oferecidas ao aluno respondente, pedimos que assinalasse apenas uma. Mais de $70 \%$ dos alunos esperam que o curso ofereça uma formação profissional voltada para o mercado de trabalho.

Nesse momento, objetivando concluir o levantamento de dados acerca dos aspectos educacionais dos alunos, foi-Ihes solicitado que, entre cinco alternativas oferecidas, escolhessem uma que resumisse suas intenções ao término do curso. Trabalhar e prosseguir estudando foi a alternativa apontada por mais de $42 \%$ dos respondentes. Prosseguir com os estudos (tentar a Universidade) foi a segunda alternativa, assinalada por mais de $29 \%$ dos alunos. 


\section{DISCUSSÃO}

Mesmo que possamos especular que a maioria dos cursos técnicos esteja voltada para o sexo masculino, a tendência de a mulher escolarizar-se mais que o homem confirma-se por meio dos dados, não apenas nesta, mas na maioria das pesquisas que apresentam dados advindos de um censo que inclua a aferição de gênero no sistema educacional brasileiro. Trata-se de uma confirmação que se verifica por meio de dados históricos, ou seja, temos uma população com superioridade numérica feminina. E isso se confirma também na escola.

No censo do Instituto Brasileiro de Geografia e Estatística (2010), os resultados preliminares apontam para 51,04\% de população feminina, cerca de 97 milhões de mulheres, e $48,96 \%$ de homens, por volta de 93 milhões de pessoas do sexo masculino, de um total de 190.732.694 habitantes.

Apesar de, no nascimento, o número de pessoas do sexo masculino ser superior, quando se aborda o assunto desde a adolescência, esse número se inverte por razões inúmeras já estudadas e de conhecimento geral. Portanto, um perfil começa a ser delineado ao confirmarmos que se trata de uma população com uma pequena predominância do sexo feminino.

Na questão de gênero, reproduz-se o espectro nacional, quanto à idade. Já despontam algumas peculiaridades. Encontramos uma população que foge muito do ideal em relação ao que se espera no Ensino Médio ou seu equivalente no Ensino Profissionalizante. Esse dado, em nossa pesquisa, variou de 15 a 59 anos, e a média dessa população ficou em 24,12 anos (desvio-padrão: 8,3). A idade esperada para essa população gira em torno de 15 a 18 anos. Concluímos, para início de construção do perfil dos alunos que optaram por cursos técnicos, que se trata de uma população mais madura, já desprovida dos arroubos juvenis que caracterizam a população adolescente

A maioria dos alunos é solteira $(68,7 \%)$, não possui filhos (74\%) e ainda mora com os pais (64,3\%). Estamos comprovando um novo fenômeno, denominado por alguns estudiosos como adolescência tardia, em que a pessoa continua morando com os pais, apesar de já ter idade para sair de casa e partir para uma vida mais independente. A necessidade de mais e mais especializações e aperfeiçoamentos para um mercado de trabalho cada vez mais exigente e seletivo vem adiando a saída do jovem da casa da família, uma vez que a dedicação à carreira profissional tem superado os desejos de construção da independência emocional e financeira dos pais. Essa é uma das explicações plausíveis.

Outro aspecto dessa população é que podemos afirmar se tratar de uma população "plugada" nas novidades e novas tecnologias. Ao agruparmos algumas respostas, explicitadas na Tabela 2, atingiríamos quase $85 \%$ em média de respostas afirmativas quando o respondente era convidado a se manifestar acerca da utilização de novas tecnologias.

Ademais, muito nos entusiasmou a constatação da interatividade das pessoas, pois, ao contrário do que parece, as novas tecnologias têm proporcionado, ao menos para esse grupo, vários tipos de interação, presencial essencialmente. Note-se que $71,7 \%$ dos alunos afirmaram possuir computador com acesso à internet em casa, o que é essencial para se usar o correio eletrônico. No entanto, $96,4 \%$ dos alunos afirmaram possuir e-mail, o que sugere essa interatividade, pois mais de $24 \%$ dos alunos não teriam meios para enviar ou receber mensagens, senão por meio da escola ou da utilização de aparelhos de outras pessoas, conectados à internet. Com o Orkut $(79,7 \%)$ e o MSNMessenger (91,2\%), guardadas as devidas proporções, podemos inferir o mesmo.

A situação trabalhista da população pesquisada apresenta alguns índices que devem ser analisados. Mais de $42 \%$ da população em pauta trabalha com carteira assinada. Essa informação significa, além do correto procedimento envolvendo patrões e empregados, que o aluno (trabalhador) que traz sua carteira de trabalho assinada traz também a segurança de poder cursar e cuidar dos afazeres decorrentes da educação, sem que esse fato represente uma ameaça ao seu emprego. A carteira de trabalho devidamente assinada garante alguns benefícios dos quais o trabalhador informal não dispõe. De todo modo, os que trabalham, com ou sem a carteira de trabalho assinada, são mais de $60 \%$. Um adendo é importante, nesse momento, diante dos dados apresentados. Verificamos, na Tabela 3, que mais de 36\% dos alunos pesquisados afirmaram que não trabalham. Era comum a ideia de que a Escola Técnica atenderia ao trabalhador ou aos seus filhos com objetivos claros de empregabilidade imediata. Notamos, atualmente, que a ideia de uma Escola Técnica, cuja formação era direcionada objetivamente à aprendizagem de ofícios, e que estes garantiriam a colocação no mercado de trabalho, geralmente em empregos de baixa renda ou subempregos, não se sustenta mais.

Podemos afirmar que se trata de uma população trabalhadora, pois os que trabalham com carteira assinada $(42,2 \%)$ mais os que trabalham eventualmente $(19,5 \%)$ somam um total de $61,7 \%$ do alunado; no entanto, há de se considerar o contingente de não trabalhadores $(36,8 \%)$ e, eventualmente, $19,5 \%$ de pessoas, que somariam $56,3 \%$ de pessoas fora do mercado de trabalho. 
O último aspecto retratado pela Tabela 3 diz respeito ao lazer. Nessa tabela, é notória a presença da internet. Se nas décadas passadas a TV reinava absoluta, atualmente tem que dividir espaços. Entre as cinco opções oferecidas, pedimos aos respondentes que assinalassem uma única opção, e a internet foi lembrada por $28,3 \%$ dos alunos, seguida pelos amigos (20,5\%) e pela TV $(20,2 \%)$.

Os dados constantes na Tabela 4 permitiram-nos registrar a classificação socioeconômica, segundo os critérios da Abipeme.

O pai é a pessoa que mais contribui financeiramente em $42,2 \%$ dos casos registrados por meio do questionário aplicado. O próprio aluno, em 19,5\% dos casos, é o contribuinte financeiro majoritário, e a mãe, como principal contribuinte financeiro, perfaz um total de 19,1\% da amostra.

É importante notarmos que $61,3 \%$ dos respondentes apontam o pai ou a mãe como responsável pelo sustento financeiro do lar. É legítimo indicarmos, ainda, que a maioria dos alunos respondentes do questionário aplicado é dependente financeiro da família (pai ou mãe).

A Tabela 4 torna visível, pelos dados, a predominância do Ensino Médio como nível de instrução tanto dos pais quanto das mães. Mais uma vez não nos surpreendem os dados obtidos, pois refletem comportamentos e atitudes já conhecidos, debatidos e até mencionados neste e em outros trabalhos. A mulher tem mais tempo de escolarização do que o homem. Enquanto $29 \%$ dos homens formaram-se em curso superior, entre as mulheres esse número salta para $40 \%$, em nossa amostra, demonstrando, mais uma vez, que a mulher tem mais presença no setor educacional. $\mathrm{E}$ lembrando sempre que tais dados referem-se ao interior do estado de São Paulo e, portanto, de cautelosa generalização.

É possível identificarmos, na Tabela 4, a predominância das classes B e C, que, juntas, compõem mais de $90 \%$ do alunado que optou pelos cursos técnicos na escola investigada. Notamos uma concentração de alunos pertencentes às classes $B$ e $C$ e uma drástica diminuição nas classes extremas, A e D. É bom ressaltarmos, contudo, que o critério da Abipeme leva em consideração a posse de bens e serviços, bem como a escolaridade dos responsáveis pelo sustento da casa, não se preocupando com faixas salariais. O que se destaca, ainda na Tabela 4, é a grande quantidade de pais aposentados, cuja idade justificaria o grande número de alunos (seus filhos) com idade superior ao esperado nessa faixa escolar, como já ressaltamos.

A Tabela 5 reúne informações acerca da situação educacional do aluno respondente. Quando solicitados a explicitar onde cursaram o Primeiro Grau, atual Ensino Fundamental, 89,7\% afirmaram tê-lo cursado em escola pública. Vemos, portanto, que se trata de população oriunda do Ensino Público.
A Tabela 5 também ilustra de forma clara que o aluno que opta pelos cursos técnicos apresenta certa maturidade, pois justifica sua escolha, por este ou aquele curso, apontando com maior frequência três alternativas oferecidas que nos levam a considerá-lo como tal. Vejamos. Mais de $60 \%$ dos respondentes anotaram a "qualidade do curso oferecido" como o principal motivo para a escolha do curso que está realizando; acima de $45 \%$, de modo a chamar-nos a atenção, importaram-se com a "disponibilidade de vagas no mercado de trabalho"; e, por fim, mais de $43 \%$ apontaram a "realização pessoal". É fácil deduzirmos daí que o aluno importa-se com a qualidade daquilo que vai receber e que, apesar de ser uma escola pública, a qualidade do serviço oferecido pode ser muito boa; porém, não adianta receber uma formação de qualidade se o mercado de trabalho não absorver a mão de obra especializada. Por fim, nada disto - qualidade de ensino, garantia de empregabilidade importa, se não houver realização pessoal. Nessa questão, foi oferecido um leque de 13 alternativas, e a concentração das respostas nas três opções citadas chancela a maturidade do grupo pesquisado.

Essa preocupação com o mercado de trabalho é explicitada em outra questão, na qual solicitamos que os respondentes se posicionassem sobre o que esperam do curso. Verificamos que $71,7 \%$ dos alunos assinalaram que esperam receber uma formação voltada para o mercado de trabalho. Nessa oportunidade, propusemos quatro alternativas e solicitamos que apontassem apenas uma.

A Tabela 5 ainda registra o desejo dos alunos respondentes quanto ao futuro imediato. A grande maioria, $95 \%$, mostrou ter muito bem definidas quais as suas expectativas quanto ao futuro profissional. Futuro este, de curto prazo, pois "trabalhar e estudar", "prosseguir com os estudos na Universidade" ou "trabalhar na área" significam um tempo de, no máximo, dois ou três semestres, considerando-se que os cursos técnicos têm uma duração máxima de quatro semestres.

A tentativa de construirmos um perfil do aluno que opta pelos cursos técnicos mostrou-se possível ao final da análise do questionário aplicado. É possível afirmarmos que se trata de uma população com uma pequena superioridade numérica feminina, nascida, em sua maioria, na cidadesede da escola, com idade média em torno de 24 anos, que estuda no período noturno, oriunda da escola pública, solteira, sem filhos, que mora com os pais, muito interessada nas novas tecnologias, que trabalha, que apresenta objetivos claros e espera uma boa formação voltada para o mercado de trabalho. Além disso, essa população pretende, num curto prazo, trabalhar e continuar os estudos universitários, entende que a internet, os amigos e a televisão atendem às suas necessidades de lazer e depende financeiramente dos 
pais, que, por sua vez, apresentam o Ensino Médio completo como nível de escolarização e trabalham, em sua maioria, na área de serviços. Os respondentes caracterizam-se por pertencerem às classes socioeconômicas B e C.

\section{CONSIDERAÇÕES FINAIS}

O interesse pelos cursos técnicos vem aumentando muito, tanto que as matrículas cresceram 74,9\% entre 2002 e 2010, segundo os dados colhidos no portal do Ministério da Educação e Cultura. Em 2002, o número de jovens matriculados nessa modalidade de ensino no país chegava a pouco mais de 650 mil alunos. Em 2010, esse número saltou para mais 1,1 milhão.

Na Escola Técnica onde realizamos nossa coleta de dados, somavam-se, no primeiro semestre de 1998, um total de 121 alunos matriculados em três distintos cursos, a saber, Técnico em Administração, em Contabilidade e em Mecânica. Já em 2004, com a oferta de mais três cursos (Técnico em Meio Ambiente, em Enfermagem e em Assessoria de Gerenciamento Empresarial), registrou-se um total de 465 alunos matriculados (HEMÉRITAS; MAIA, 2005). Um crescimento na matrícula de mais de $380 \%$ em pouco mais de cinco anos.

Para Heméritas e Maia (2005, p. 81, grifo nosso), o perfil do aluno do "Centro Paula Souza é hoje (2005), em relação ao ano de 1997, mais pobre, mais velho e constituído por mais pessoas que trabalham".

Segundo os dados por nós obtidos, por meio do critério da Abipeme, os alunos que pertencem às classes socioeconômicas B e C, e que somam mais de $90 \%$, também fariam parte dessas classes, caso tivéssemos utilizado outro critério que usasse a renda familiar como determinante da classe.

No estudo de Heméritas e Maia (2005), os autores afirmam que, em 2004, 66,6\% dos alunos apresentavam renda familiar entre 0 e 5 salários-mínimos, algo em torno de $R \$ 1.300,00$. Hoje (2011), podemos afirmar que mais de $90 \%$ dos alunos pesquisados localizam-se nas classes B e C. Em 2004, a maioria dos alunos pertenceria à classe D, enquanto as classes B e C, que hoje despontam, estariam recebendo salários em torno de três a cinco mil reais, que corresponderia à faixa de 5 a 10 salários-mínimos.

Portanto, é possível concluirmos, perante os dados por nós obtidos mediante a utilização do critério da Abipeme, que os alunos da Escola Técnica Estadual pesquisada, em 2011, são oriundos de estratos econômicos mais elevados do que em 2004.

O outro aspecto levado em consideração no estudo de Heméritas e Maia (2005), visando à construção do perfil do alunado, refere-se à faixa etária. Nesse estudo, os autores concluem "que os alunos (2004), em média, estão com idade superior à do ano de 1995" (Heméritas; Maia, 2005, p. 79).

Em 1995, 83\% dos alunos apresentavam idade entre 15 e 17 anos, muito dentro da expectativa que se tem sobre a relação entre idade e seriação ideal. Notamos, por meio desse estudo, que a população foi amadurecendo, com o passar dos anos, chegando em 2004 com 40,3\% dos alunos matriculados na faixa etária entre 18 e 27 anos.

A média de idade dos alunos respondentes, em nossa investigação, é de 24 anos. Para que possamos ter uma visão geral desse quesito, adaptamos os dados obtidos recentemente e construímos uma tabela que mostra a idade dos alunos desde o primeiro levantamento até os dias de hoje.

Tabela 6 - Faixa etária através dos anos

\begin{tabular}{lccc}
\hline & $\mathbf{1 5 - 1 7}$ anos & $\mathbf{1 8 - 2 7}$ anos & Mais de 27 anos \\
\hline $1995 *$ & $83,00 \%$ & $17,00 \%$ & -- \\
$1998 *$ & $22,00 \%$ & $62,00 \%$ & $16,00 \%$ \\
$2002 *$ & $24,42 \%$ & $57,01 \%$ & $18,57 \%$ \\
$2003 *$ & $33,46 \%$ & $49,92 \%$ & $16.62 \%$ \\
$2004 *$ & $33,30 \%$ & $40,30 \%$ & $14,72 \%$ \\
$2011 * *$ & $21,45 \%$ & $51,66 \%$ & $26,88 \%$ \\
\hline
\end{tabular}

*Dados obtidos do estudo de Heméritas e Maia (2005, p.78).

**Dados nossos, adaptados ao formato do estudo citado, para mera comparação.

Um dado muito interessante e com óbvia explicação é o aumento gradual de pessoas acima de 27 anos. Observa-se que, em 1995, não foi registrado sequer um aluno nessa faixa etária. Em 2011, houve um significativo salto para além de $25 \%$ de alunos com idade superior a 27 anos. Esse fato pode ter ocorrido em razão de, em 2008, ter sido sancionada pelo Presidente da República a Lei n 11.741, na qual, resumidamente, desvinculam-se os cursos técnicos do Ensino Médio, ou seja, o interessado pode cursar o Ensino Médio numa Instituição e, concomitantemente, o curso técnico em outra. Ou ainda, tê-lo já concluído (Ensino Médio) e estar propenso a cursar uma modalidade de seu interesse, situação mais comum atualmente.

Como já mencionamos, Heméritas e Maia (2005, p. 81) concluem que o aluno de 2004, em relação ao ano de 1997, "é mais pobre, mais velho e constituido por mais pessoas que trabalham".

A fim de resumir, como o fizeram Heméritas e Maia, o alunado hoje (2011) é, em relação a 2004, mais rico, mais velho e apresenta uma porcentagem maior de alunos trabalhadores.

O aluno mais velho, que ora está na escola, necessita de mais estudos e investigações, pois sabemos da importância 
de se obterem mais informações, na tentativa de desvelar essa parcela que se faz muito presente. Entendê-lo para poder agir em seu benefício é o que desejamos. Somos sabedores das dificuldades que os desencontros de interesses entre o corpo discente e docente, por exemplo, poderiam causar no ambiente escolar.

Porém, além de pesquisadores, somos educadores preocupados com o atual momento social, político e educacional que vivenciamos. Existem vagas no mercado de trabalho formal que não estão sendo preenchidas por pura falta de formação do postulante a ela, e isso é notícia diária. Ora, não serão os cursos técnicos, isoladamente, a despeito do esforço de seu corpo dirigente e docente, sempre muito pontual e interessado, que resolverão os problemas estruturais de uma nação como o Brasil. E também não é verdade, como alardeado pela imprensa, que cursar o Ensino Técnico é certeza de empregabilidade.

Por fim, a escola pública deve fazer parte das responsabilidades da Universidade, pois ela (a escola pública) sempre nos serviu como um grande laboratório onde se mapeia toda uma problemática e pouco se produz no sentido prático. Não devemos nos propor tutores e sim colaboradores, pois não é difícil visualizar que a Escola Técnica, atualmente, em muitos casos, está sendo administrada com muita competência e sabendo caminhar por estradas, em que a criatividade de seus dirigentes faz a diferença.

Não nutrimos a ilusão de conseguir fazer deste um trabalho voltado para as soluções na escola técnica, mas nos sentiremos satisfeitos se provocarmos uma reflexão que possa produzir ações, com o intuito de despertar a responsabilidade que cada um tem na construção de um mundo mais justo, de uma escola mais competente.

\section{REFERÊNCIAS}

ARAPIRACA, José Oliveira. A Usaid e a educação brasileira. São Paulo: Cortez, 1982.

BAENINGER, Rosana; JANNUZZI, Paulo de Martino. Qualificação socioeconômica e demográfica das classes da escala Abipeme. Revista de Administração da Universidade de São Paulo, São Paulo, v. 31, n. 3, p. 81-90, jul./set. 1996.

BIAGINI, Jussara. Revisitando momentos da história do ensino técnico. Disponível em: <http://www.ufop.br/ichs/ conifes/anais/EDU/edu1713.htm>. Acesso em: $10 \mathrm{abr}$. 2012.
BRASIL. Ministério da Educação. Centenário da Rede Federal de Educação Profissional e Tecnológica. Brasília, DF, 2009.

Ministério da Educação. Ministério do Trabalho. Reforma do Ensino Técnico. Brasília, mar. 1996.

Ministério da Educação. Notícias SETEC Secretaria de Educação Profissional e Tecnológica, n 173, 20 a 26/08/2007, Brasília, DF, 2007.

Secretaria de Formação e Desenvolvimento

Profissional. Ministério do Trabalho. Educação profissional: um projeto para o desenvolvimento sustentado. Brasília, ago. 1995.

CUNHA, Luiz Antonio. O ensino de ofícios artesanais e manufatureiros no Brasil escravocrata. 2. ed. São Paulo: Ed. Unesp; Brasília: FLACSO, 2005a.

O ensino de ofícios nos primórdios da industrialização. 2. ed. São Paulo: Ed. Unesp; Brasília: FLACSO, 2005b.

O ensino profissional na irradiação do industrialismo. 2. ed. São Paulo: Ed. Unesp; Brasília: FLACSO, 2005c.

FERRETTI, Celso João. Formação profissional e reforma do ensino técnico no Brasil: Anos 90. Educação \& Sociedade, Campinas, ano XVIII, n. 59, p. 225-269, ago. 1997.

FONSECA, Celso Suckow. História do ensino industrial no Brasil. Rio de Janeiro: Escola Técnica, 1961.

GOES, Moacyr de; CUNHA, Luiz Antonio. O golpe na educação (Brasil: os anos de autoritarismo). Rio de Janeiro: Zahar, 1985.

HEMÉRITAS, Ademar. Batista; MAIA, Luís Carlos Zanirato. Reflexos da reforma da educação profissional nas escolas técnicas de São Paulo. Campinas: Komedi, 2005.

KUENZER, Acácia Zeneida. Ensino médio e profissional: as políticas do estado neoliberal. São Paulo: Cortez, 2000.

LÜDKE, Menga; ANDRÉ, Marli Eliza Dalmazo Afonso de. Pesquisa em educação: abordagens qualitativas. São Paulo: EPU, 1986.

MACIEL, Lizete S. Bomura; SHIGUNOV, Alexandre. O ensino jesuítico no período colonial brasileiro: algumas discussões. Educar, Curitiba, v. 31, p. 169-189, 2008. 
MENEZES, Ebenezer Takuno de; SANTOS, Thais Helena dos. "MEC/USAID" (verbete). Dicionário interativo da educação brasileira - EducaBrasil. São Paulo: Midiamix, 2002. Disponível em: <http://www.educabrasil.com.br/ eb/dic/dicionario.asp?id=325>. Acesso em: 26 abr. 2012.

OLIVEIRA, Ramon de. A (des)qualificação da educação profissional brasileira. São Paulo: Cortez, 2003.

ROMANELLI, Otaíza de Oliveira. História da educação no Brasil. Petrópolis: 1978.

SABLICH, Cynthia. Os sistemas educacionais do Brasil e da Coréia do Sul: Uma avaliação da valorização do capital humano como fator determinante para o crescimento econômico ocorrido a partir da década de 70. 2007. Monografia (Graduação em Economia) - Centro de Ciências Sociais e Aplicadas, Universidade Presbiteriana Mackenzie, São Paulo, 2007.

Recebido em: 31/03/2014

Aceito em: 16/09/2014 